\title{
Pelatihan pola pengasuhan menghadapi anak trauma
}

\author{
Alfiandy Warih Handoyo \\ Faculty of Teacher Training and Education, Universitas Sultan Ageng Tirtayasa, \\ Indonesia
}

*alfiandywh@yahoo.com

\begin{abstract}
Sleman district has the high-risk potential of the natural disaster. Disaster risk has positive correlate to potential trauma risk, especially on children. Trauma will be rise direct after a disaster or delay or called posttraumatic stress disorder (PTSD). Parents are the most influential party to the child's development, so parents in disaster-prone areas must have the skills to deal with a traumatized child. The handling of trauma given to victims of natural disasters in Sleman Regency is only based on direct handling post-disaster. There is no advisory service for parents in dealing with traumatized children. Training needs to be given to parents, especially residents in locations that have a high potential for natural disasters. The training aims to provide readiness for parents to accompany traumatized children so that the impact of the trauma does not get worse. Based on the results of the application, it is proven that parents can perform parenting skills to assist traumatized children.
\end{abstract}

\begin{abstract}
Abstrak Kabupaten Sleman memiliki potensi bencana alam yang tinggi. Tingkat potensi bencana alam memiliki korelasi positif dengan potensi terjadinya trauma, khususnya pada anak. Trauma bisa terjadi langsung atau beberapa saat setelah kejadian yang disebut dengan posttraumatic stress disorder (PTSD). Orang tua menjadi pihak yang paling berpengaruh pada perkembangan anak, sehingga orang tua di daerah rawan bencana harus memiliki keterampilan penanganan trauma anak. Penanganan trauma yang diberikan kepada korban bencana alam di Kabupaten Sleman hanya berbasis pada penanganan langsung pasca bencana. Belum ada layanan pendampingan bagi orang tua dalam menghadapi anak trauma. Perlu dilakukan pelatihan yang diberikan kepada orang tua khususnya warga di lokasi yang memiliki potensi bencana alam yang tinggi. Tujuan pelatihan adalah memberikan kesiapan bagi orang tua untuk mendampingi anak trauma sehingga dampak trauma tidak semakin parah. Berdasarkan hasil penerapan, terbukti orang tua mampu melakukan keterampilan pengasuhan mendampingi anak trauma.
\end{abstract}

Keywords: parenting class; trauma; PTSD; child; parent; disaster

\section{OOPEN ACCESS}

Citation: Handoyo, A.W. (2020). Pelatihan pola pengasuhan menghadapi anak trauma. Riau Journal of Empowerment, 3(3), 171-182. https://doi.org/10.31258/raje.3.3.171-182

Paper type: Community service

Received: 2019-12-30 Revised: 2020-09-12 Accepted: 2020-09-14

Language: Bahasa Indonesia (id)

ISSN 2623-1549 (online), 2654-4520 (print)

C 2020 Alfiandy Warih Handoyo. Author(s) retain the copyright of article published in this journal, with first publication rights granted to Riau Journal of Empowerment. The article is licenced under Creative Commons Attribution 4.0 International License. This license permits unrestricted use, distribution, and reproduction in any medium, provided the original author and source are credited. 


\section{PENDAHULUAN}

Bencana alam menjadi salah satu diantara banyak penyebab individu mengalami stres (Afiati et al., 2020). Stres dan trauma akan yang berkelanjutan sering disebut dengan posttraumatic stress disorder (PTSD). PTSD terjadi saat seseorang mengalami atau mengetahui suatu hal atau fenomena yang dianggap diluar kewajaran (Kinchin, 2007). Anak-anak cenderung lebih rentan terhadap efek dari peristiwa traumatis dibandingkan dengan orang dewasa (National Comision on Children and Disaster, 2010). Salah satu contoh, setelah kejadian banjir Nashfile tahun 2010, banyak anak sekolah yang dideteksi mengalami depresi bahkan menjurus PTSD karena tidak memiliki pengalaman dam pengetahuan tentang banjir (Felton et al., 2013). Riset yang dilakukan Newman et al. (2014) menunjukkan, anak yang tidak segera mendapat penanganan baik setelah diindikasi mengalami trauma, cepat atau lambat akan segera mengalami PTSD yang berkelanjutan.

Trauma juga bisa dialami oleh orang dewasa. Apabila sorang dewasa, khususnya orang tua mengalai trauma, memiliki potensi bahaya yang lebih besar. Penelitian terhadap anak-anak dari orang tua korban kejadian Holocaust Nazi menunjukkan kecenderungan, mereka mengalami ketakutan dan hidup dalam rasa tertekan selama bertahun-tahun akibat ketakutan yang dimiliki orang tuanya (Fossion et al., 2013). Apabila terdapat orang tua yang terindikasi sebagai penderita PTSD, maka anak juga memiliki potensi untuk mengalami penyimpangan perilaku akibat pola asuh orang tua yang kurang tepat yang dilakukan oleh orang tuanya (Creech \& Misca, 2017). Penelitian yang dilakukan oleh Samuelson et al. (2017) menunjukkan bahwa anak dengan orang tua penderita PTSD akan mengalami kesulitan untuk mengembangkan beberapa nilai positif dalam kehidupannya.

Salah satu hal yang mempengaruhi trauma pada individu adalah faktor trauma yang dimunculkan oleh lingkungan keluarga (Cobham \& McDermott, 2014). Anak akan tergantung kepada orang tuanya, dan apa yang ditunjukkan anak adalah apa yang dilihat dari orang tuanya (Sung \& Park, 2012). Secara garis besar skema ini merupakan skema yang bisa dipaparkan dalam konsep pengasuhan dan gambaran diri yang dikembangkan oleh Sullivan. Menurut Sullivan dalam Hall dan Lindzey (1985), pengasuhan orang tua merupakan pendidikan kepribadian yang diterima oleh anak pertama kali. Feist dan Feist (2006) menyebutkan, pada anak usia 2-6 tahun, peranan pengasuhan orang tua menjadi sangat utama dalam membentuk kepribadian anak. Russel et al. (2010) mengemukakan bahwa pola asuh orang tua akan memiliki kaitan erat dengan penyesuaian seorang anak pada lingkungannya.

Dampak buruk dari pengasuhan yang kurang tepat akan terasa jika anak sudah dewasa terlebih jika hal tersebut merupakan suatu trauma (Sriskandarajah et al., 2015). Pola asuh yang berbeda akan menimbulkan dampak yang berbeda pada anak ketika dewasa (Uji et al., 2014). Stres pengasuhan adalah perasaan bingung, frustrasi, dan kesulitan yang dianggap sebagai suatu tekanan dalam kegiatan pengasuhan anak (Hutchison et al., 2016; Mackler et al., 2015). Roustit et al. (2010) membuktikan bahwa stres yang dialami orang tua memberi kontribusi 615 persen penyimpangan yang dilakukan oleh remaja. Stres yang dialami saat mengasuh anak akan menghambat perkembangan bahasa anak sehingga anak akan mengalami penyimpangan karena gagal mengembangkan komunikasi yang baik. Trauma sendiri merupakan salah satu dampak bencana yang lebih berat daripada stres (Butler et al., 2017). Pada akhirnya pola pengasuhan yang baik akan memberikan dampak yang baik pula.

Kabupaten Sleman merupakan salah satu kabupaten dengan potensi bencana alam yang cukup kompleks, salah satunya erupsi gunung Merapi. Secara alamiah, gunung ini memiliki 
siklus letusan rutin 5, 10 dan 100 tahunan. Pada tahun 2010 kemarin, Merapi mengalami siklus 100 tahunannya dimana itu merupakan siklus erupsi terbesar. Berdasarkan data BPBD, erupsi Merapi tahun 2010 memberikan dampak secara langsung pada tiga kabupaten, Sleman, Magelang, dan Boyolali. Kabupaten Sleman, tercatat sebagai kabupaten dengan korban paling banyak. Setidaknya ada 246 jiwa meninggal dunia dari 3 kecamatan terdampak langsung erupsi gunung Merapi. Kerusakan yang paling parah dialami oleh kecamatan Cangkringan. Pada kecamatan ini tercatat ada seluruh kelurahannya menjadi korban erupsi Merapi dan yang paling parah dialami oleh kelurahan Kepuharjo dimana hampir seluruh pedusunan dalam kecamatan ini luluh lantak sehingga terpaksa direlokasi. Selain itu Kepuh Harjo merupakan kelurahan dengan pengurangan jumlah penduduk terbanyak antara sebelum dan sesudah erupsi merapi 2010.

Komplek Hunian Tetap Kepuharjo merupakan komplek desa relokasi karena menjadi korban erupsi Gunung Merapi 2010. Dalam komplek hunian tetap (desa relokasi) ini terdiri atas tiga Pedukuhan, Ngangrong, Kinahrejo, dan Petung. Pedukuhan Kinahrejo dan Petung merupakan Pedukuhan yang awalnya berjarak 7 kilometer dari puncak gunung Merapi. Pedukuhan Petung sendiri pada awalnya memiliki 114 kepala keluarga yang tercatat sebagai korban Merapi. Warga Pedukuhan Petung sendiri tercatat ada 1 orang yang meninggal saat terjadi erupsi Merapi 2010. Selain korban nyawa, semua harta benda warga yang berada dalam rumah, termasuk fisik rumah warga Petung tidak ada yang terselamatkan.

Penanganan pasca bencana sendiri belum terlalu dikelola dengan baik. Berdasarkan penuturan Bapak Pairin, Kepala Pedukuhan Petung, pemerintah masih terlalu fokus pada masalah pembangunan fisik. Tentang aspek psikologis hanya terjadi di awal bencana saja. Hal tersebut dirasa sangat miris karena dalam DSM IV, justru trauma akan muncul beberapa saat, 1 sampai 5 tahun pasca bencana. Salah satu program pendampingan trauma yang pernah dirasakan warga Pedukuhan Petung hanya diberikan kepada anak-anak. Meskipun demikian, karena hanya bersifat saat terjadi bencana, bisa saja trauma anak terjadi saat dia sudah dewasa. Untuk menghindari terjadi hal tersebut, perlu diberikan pemahaman bagi orang tua bagaimana menangani rasa trauma yang dimiliki orang tua atau jika hal tersebut dialami oleh anaknya.

Salah satu faktor yang mempengaruhi pola asuh yang diterapkan kepada anak adalah tingkat stres pengasuhan orang tua (Shreffler et al., 2011). Ada keterkaitan erat antara stres yang timbul pasca bencana, pengasuhan orang tua, dan perkembangan anak dalam kaitannya dengan PTSD (Hafstad et al., 2012). Pola asuh yang buruk tersebut bisa saja muncul karena orang tua yang stres karena menghadapi anak yang mengalami trauma atau sebaliknya, orang tua yang merasa tertekan karena mengalami bencana alam dan kehilangan hal-hal yang dianggap penting dalam hidupnya.

Anak-anak rentan mengalami kecemasan bahkan trauma. Beberapa faktor yang mengakibatkan kecemasan dan trauma anak antara lain perceraian orang tua, berpisah dengan orang tua, lingkungan yang baru, dan bencana alam. Menghadapi anak yang mengalami gangguan kecemasan atau trauma membutuhkan keterampilan-keterampilan khusus agar trauma pada anak tidak berlanjut menjadi PTSD. DeGangi dan Kendall (2008) menyebutkan beberapa tindakan yang dapat dilakukan orang tua dalam menghadapi anak dengan gangguan kecemasan sebagai berikut.

a. Validation (validasi). Tindakan pertama yang perlu dilakukan oleh orang tua dalam menghadapi anak yang memiliki gangguan kecemasan adalah meyakinkan kepada anak, orang tua memahami kondisi atau perasaan anak. Validasi tidak sebatas mengatakan "Aku mengerti apa yang kamu rasakan". Orang tua harus mampu meyakinkan, orang tua berada 
pada "pihak" anak dan memahami pendapat anak sekalipun irasional. Poin utama pada tahapan validasi adalah orang tua tidak menganggap atau mengatakan apabila pendapat atau ketakutan anak merupakan hal yang konyol. Orang tua yang bijak akan menjelaskan, rasa yang dialami merupakan ketakutan anak, bukan kondisi sesungguhnya.

b. Child-centered time (aktivitas berpusat pada anak). Menangani ketakutan anak artinya membuat anak merasa nyaman dan aman. Anak perlu merasa memiliki kendali penuh atas lingkungan sekitar. Upaya yang dapat dilakukan orang tua adalah memberikan perhatian sepenuhnya kepada anak seperti dengan membebaskan anak bercerita atau bermain sendiri. Upaya lain yang dapat dilakukan orang tua adalah mengajak bermain bersama dan mengikuti semua perintah anak seperti membuat mainan dari lego. Bermain bersama anak 10-20 menit per hari, dapat membantu mengurangi kecemasan anak karena anak merasa memiliki kekuatan untuk mengendalikan lingkungan.

c. Exposure (pemaparan). Prinsip utama dalam menangani ketakutan anak, adalah anak dapat terbiasa menghadapi ketakutan diri sendiri, yang juga disebut dengan exposure. Trauma muncul ketika individu menganggap peristiwa yang dialami diluar kebiasaan dan kewajaran. Trauma yang terjadi pada anak juga disebabkan anak menganggap peristiwa yang dialami diluar kewajaran anak. Orang tua memiliki tugas untuk membiasakan anak menghadapi dan mengingat kembali peristiwa traumatik agar anak menjadi lebih pandangan yang lebih baik terhadap peristiwa traumatik. Mengajak anak mengingat peristiwa traumatik bukan upaya yang mudah. Orang tua perlu menjelaskan tujuan dari proses exposure dan sedapat mungkin membuat anak menyetujui proses exposure. Mengajak anak mengingat kembali peristiwa traumatik tidak perlu dilakukan secara bertahap dan sedapat mungkin dikemas dalam aktivitas yang menyenangkan seperti bermain peran, menggambar, atau bepergian sambil mengunjungi lokasi kejadian peristiwa traumatik.

d. Play therapy (terapi bermain) Orang tua akan membutuhkan bantuan dari petugas profesional dalam menghadapi anak dengan permasalahan trauma. Metode yang dapat dilakukan dalam upaya pemberian terapi kepada anak adalah play therapy. Pada tahapan play therapy seyogyanya melibatkan orang tua dalam melakukan aktivitas. Melibatkan orang tua dalam terapi dapat menjadikan terapi semakin efektif. Terapis juga perlu membekali orang tua dengan keterampilan dasar terapi bermain agar terapi tidak sebatas dilakukan dalam sesi bersama dengan terapis namun dapat dilakukan secara mandiri.

e. Behavior change (mengubah kebiasaan). Pada saat mengalami kecemasan, anak akan menunjukkan perbuatan-perbuatan yang tidak perlu atau aneh. Tujuan penanganan trauma pada anak adalah mengubah kebiasaan buruk yang dialami oleh anak.

f. Observing limit (membuat batasan). Kecemasan merupakan suatu perasaan yang sangat menyakitkan bagi anak. Orang tua lebih mudah untuk menenangkan anak dibandingkan memberikan kesempatan bagi anak melawan rasa kecemasan sendiri, sedangkan orang tua tidak akan selamanya bersama anak.

g. Consequence (konsekuen) Anak dan orang tua perlu konsekuen terhadap tahapan dan konsisten pada rencana yang akan dilakukan termasuk mengurangi kecemasan diri pada orang tua ketika membiarkan anak melawan rasa takut.

Orang tua merupakan pihak yang paling memiliki peran penting bagi perkembangan anak di kemudian hari (Santrock, 2011). Pengetahuan orang tua terhadap trauma akan menjadi sangat penting. Sayangnya, belum ada program yang diberikan kepada orang tua untuk hal 
tersebut. Poin-poin tersebut yang menjadikan perlu adanya program pelatihan pengasuhan bagi orang tua, terutama ibu-ibu di desa relokasi korban erupsi Merapi. Tujuan dari program ini adalah menanamkan keterampilan pengasuhan anak trauma. Harapan kedepan apabila terjadi peristiwa traumatik (erupsi gunung Merapi) orang tua bisa mereduksi potensi terjadinya trauma pada anak. Lebih jauh, diharapkan hasil kegiatan ini juga bisa disampaikan oleh warga kepada penduduk di desa lain agar keterampilan penanganan anak trauma bisa terwujud pada warga sekitar lereng Merapi.

\section{METODE PENERAPAN}

\section{Jenis dan Materi Pelatihan}

Permasalahan pengasuhan anak menjadi pembahasan yang cukup menarik pada satu dekade terakhir. Pengasuhan anak tidak sekedar merawat anak namun juga menyangkut upaya yang dapat dilakukan orang tua dalam rangka mengatasi dan mencegah potensi masalah yang ada pada anak baik sosial, emosional dan kebiasaan (Enebrink et al., 2012; Ollendick et al., 2016). Beragam upaya yang dapat dilakukan oleh orang tua dalam rangka meningkatkan keterampilan pengasuhan anak, salah satunya dengan mengikuti pelatihan. Dari beragam jenis pelatihan pengasuhan, metode yang dipilih dalam kegiatan ini adalah Parent Management Training (PMT). Dahulu PMT merupakan pelatihan yang diberikan kepada orang tua yang memiliki anak dengan permasalahan tingkah laku (Wachlarowicz et al., 2012). Seiring dengan perkembangan waktu, PMT terbukti dapat diaplikasikan untuk mencegah masalah-masalah lain pada anak (Forgatch \& Kjøbli, 2016). Pemateri pelatihan PMT dapat dilakukan oleh individu yang mempelajari ilmu psikologi seperti konselor, psikolog, psikiater, klinis, pekerja sosial, dan perawat. Selain latar belakang keilmuan dasar, menjadi pemateri PMT juga membutuhkan pengetahuan lanjut tentang kepribadian khususnya pada perkembangan anak (Eddy et al., 2013).

Materi dalam kegiatan pelatihan disesuaikan dengan konten keterampilan pengasuhan khususnya menghadapi anak trauma. Tabel 1 memaparkan ragam keterampilan, materi dan metode pelaksanaan kegiatan, indikator keberhasilan, serta metode pengukuran yang dilakukan.

Tabel 1. Konten Pelatihan

\begin{tabular}{|c|c|c|c|c|c|}
\hline Kegiatan & Tujuan & Metode & Materi & Indikator keberhasilan & Pengukuran \\
\hline $\begin{array}{l}\text { Pertemuan } 1.1 \\
\text { Keberadaan } \\
\text { (Validasi) }\end{array}$ & $\begin{array}{l}\text { Mengajarkan } \\
\text { sikap dalam } \\
\text { menghadapi anak } \\
\text { trauma }\end{array}$ & $\begin{array}{l}\text { Ceramah, } \\
\text { diskusi }\end{array}$ & Attending & $\begin{array}{l}\text { a. Orang tua mengenali } \\
\text { bentuk kecemasan } \\
\text { anak } \\
\text { b. Orang tua dapat } \\
\text { menggali kecemasan } \\
\text { pada anak }\end{array}$ & asesmen skala \\
\hline $\begin{array}{l}\text { Pertemuan } 1.2 \\
\text { Penguatan } \\
\text { positif, kegiatan } \\
\text { berpusat pada } \\
\text { anak }\end{array}$ & $\begin{array}{l}\text { Mengajarkan } \\
\text { cara membuat } \\
\text { anak nyaman }\end{array}$ & $\begin{array}{l}\text { Diskusi, } \\
\text { simulasi }\end{array}$ & $\begin{array}{l}\text { Child } \\
\text { Centered }\end{array}$ & $\begin{array}{l}\text { a. Orang tua } \\
\text { mengetahu bahwa } \\
\text { anak perlu diberikan } \\
\text { ruang untuk } \\
\text { berpendapat } \\
\text { b. Orang tua dapat } \\
\text { menerapkan cara } \\
\text { membuat anak } \\
\text { merasa nyaman }\end{array}$ & $\begin{array}{l}\text { asesmen skala } \\
\& \text { observasi }\end{array}$ \\
\hline
\end{tabular}




\begin{tabular}{|c|c|c|c|c|c|}
\hline Kegiatan & Tujuan & Metode & Materi & Indikator keberhasilan & Pengukuran \\
\hline $\begin{array}{l}\text { Pertemuan } 2.1 \\
\text { Perencanaan } \\
\text { program }\end{array}$ & $\begin{array}{l}\text { a. Mengajarkan } \\
\text { cara } \\
\text { mengajak } \\
\text { anak untuk } \\
\text { mengingat } \\
\text { peristiwa } \\
\text { trauma } \\
\text { b. Menyiapkan } \\
\text { program bagi } \\
\text { anak untuk } \\
\text { menghadapi } \\
\text { bencana }\end{array}$ & Diskusi & Exposure & $\begin{array}{l}\text { a. Orang tua } \\
\text { memahami } \\
\text { pentingnya } \\
\text { mengenalkan } \\
\text { kejadian traumatik } \\
\text { kepada anak } \\
\text { b. Orang tua dapat } \\
\text { mengingatkan anak } \\
\text { tentang kejadian } \\
\text { traumatik } \\
\text { c. Orang tua dapat } \\
\text { menyiapkan anak } \\
\text { dalam menghadapi } \\
\text { bencana }\end{array}$ & asesmen skala \\
\hline $\begin{array}{l}\text { Pertemuan } 2.2 \\
\text { Pemecahan } \\
\text { masalah }\end{array}$ & $\begin{array}{l}\text { a. Mengajarkan } \\
\text { cara } \\
\text { reframing } \\
\text { pada diri } \\
\text { sendiri dan } \\
\text { anak } \\
\text { b. Mengajarkan } \\
\text { cara } \\
\text { melakukan } \\
\text { relaksasi pada } \\
\text { anak }\end{array}$ & $\begin{array}{l}\text { Diskusi, } \\
\text { simulasi }\end{array}$ & $\begin{array}{l}\text { Behavior } \\
\text { Changing }\end{array}$ & $\begin{array}{l}\text { a. Orang tua dapat } \\
\text { melakukan } \\
\text { reframing pada diri } \\
\text { sendiri } \\
\text { b. Orang tua dapat } \\
\text { melakukan } \\
\text { reframing pada anak } \\
\text { c. Orang tua dapat } \\
\text { mengajarkan anak } \\
\text { relaksasi }\end{array}$ & asesmen skala \\
\hline $\begin{array}{l}\text { Pertemuan } 3.1 \\
\text { Pembatasan dan } \\
\text { "pengabaian" }\end{array}$ & $\begin{array}{l}\text { Melakukan } \\
\text { tindakan asertif, } \\
\text { membiarkan } \\
\text { anak } \\
\text { menghadapi } \\
\text { ketakutan }\end{array}$ & $\begin{array}{l}\text { Ceramah, } \\
\text { diskusi }\end{array}$ & Pembatasan & $\begin{array}{l}\text { a. Orang tua paham } \\
\text { adakalanya anak } \\
\text { harus berani } \\
\text { menghadapi } \\
\text { ketakutannya sendiri } \\
\text { b. Orang tua memiliki } \\
\text { keberanian untuk } \\
\text { membiarkan } \\
\text { anaknya menghadapi } \\
\text { rasa takut } \\
\text { c. Orang tua dapat } \\
\text { melakukan tindakan } \\
\text { asertif, membiarkan } \\
\text { anak menghadapi } \\
\text { ketakutan sendiri }\end{array}$ & asesmen skala \\
\hline $\begin{array}{l}\text { Pertemuan } 3.2 \\
\text { Kompromi }\end{array}$ & $\begin{array}{l}\text { a. Memahamkan } \\
\text { orang tua } \\
\text { tentang } \\
\text { perlunya } \\
\text { bersikap } \\
\text { konsekuen } \\
\text { kepada anak } \\
\text { b. Mengajarkan } \\
\text { cara } \\
\text { mendiskusika } \\
\text { n suatu } \\
\text { kesepakatan } \\
\text { bersama }\end{array}$ & $\begin{array}{l}\text { Ceramah, } \\
\text { diskusi }\end{array}$ & Konsekuen & $\begin{array}{l}\text { a. Orang tua } \\
\text { memahami perlunya } \\
\text { bersikap konsisten } \\
\text { terhadap anak } \\
\text { b. Orang tua dapat } \\
\text { melakukan diskusi } \\
\text { dengan anak terkait } \\
\text { keputusan yang akan } \\
\text { dilaksanakan } \\
\text { bersama }\end{array}$ & asesmen skala \\
\hline
\end{tabular}


Berdasarkan paparan pada Tabel 1 dapat diketahui bahwa pengukuran keberhasilan pelatihan dilakukan menggunakan metode asesmen skala serta observasi. Asesmen skala dilakukan karena dianggap lebih efektif untuk mengukur pemahaman para peserta terhadap materi yang disampaikan. Observasi digunakan untuk melihat pelaksanaan proses pelatihan karena dalam beberapa materi dilakukan dalam bentuk simulasi langsung.

Handoyo

\section{Pemilihan Partisipan}

Sasaran kegiatan pelatihan adalah para ibu korban erupsi Gunung Merapi yang memiliki anak SD hingga SMP di wilayah Pedukuhan Petung, Cangkringan, Sleman, Daerah Istimewa Yogyakarta. Berdasarkan data dari pengurus Pedukuhan setempat, terdapat 33 orang Ibu yang memiliki anak usia SD-SMP sehingga seluruhnya dilibatkan dalam kegiatan.

\section{HASIL DAN KETERCAPAIAN SASARAN}

Kegiatan pelatihan dapat meningkatkan keterampilan pengasuhan orang tua korban erupsi Gunung Merapi. Berikut dipaparkan hasil pencapaian kegiatan.

\section{Keterampilan Validasi}

Validasi adalah kemampuan orang tua untuk mengetahui keadaan, perasaan, dan kondisi yang dirasakan oleh anak (Handoyo, 2019). Mengawali sesi ini, fasilitator menjelaskan beberapa kondisi kecemasan yang dialami oleh anak. Selanjutnya dipaparkan beberapa cara yang baik dalam upaya menenangkan kecemasan anak. Fasilitator memberikan pertanyaan tentang apa saja yang perlu dilakukan untuk meyakinkan anak, terutama saat sedang cemas. Beberapa peserta menuturkan, anak harus dapat diam sendiri terutama saat orang tua sedang sibuk. Tidak jarang untuk membuat anak diam orang tua menggunakan hukuman. Fasilitator kemudian memberikan tips menggali kecemasan anak dengan baik. Beberapa faktor yang perlu diperhatikan antara lain pemilihan kata, intonasi, ekspresi wajah, senyuman, dan apabila diperlukan menggunakan pelukan dan usapan.

Orang tua secara berpasangan melakukan simulasi upaya menenangkan kecemasan anak. Jumlah peserta ganjil, menyebabkan ada seorang peserta (ED) yang tidak mendapat pasangan sehingga diminta untuk menjadi pengamat. Digambarkan situasi peserta sebagai orang tua sedang sibuk di dapur dan anak mendadak menangis. Pemeran orang tua diminta menenangkan anak dan menggali kecemasan anak.

\section{Aktivitas berpusat pada anak}

Salah satu cara kreatif untuk mengetahui perasaan anak adalah membiarkan anak berekspresi (Kottman, 2014). Sesi ini memiliki tujuan untuk membekali orang tua dengan keterampilan beraktivitas secara edukatif bersama anak. Pada awal sesi para peserta dibagi menjadi 4 kelompok. Masing-masing kelompok diberikan satu set mainan anak. Para peserta diminta secara berpasangan untuk memerankan orang tua dan anak. Pemeran orang tua bertugas untuk mengajak anak bermain dan membiarkan anak bebas bercerita dengan mainan. Pada awalnya para peserta masih agak kebingungan dengan apa yang harus dilakukan. Secara tidak sengaja para anak yang ada di sekitar lokasi pelatihan tertarik untuk masuk karena melihat banyak mainan di depan para orang tua. Anak-anak yang berada di sekitar lokasi pelatihan kemudian 
masuk dan memainkan mainan yang ada di hadapan para orang tua. Fasilitator kemudian menginstruksikan agar semua peserta bermain bebas dengan anak masing-masing.

Kondisi yang tidak terencana justru membuat simulasi seolah lebih natural tanpa ada pengkondisian. Anak-anak dengan alami memainkan boneka dan mainan sedangkan orang tua diminta mengikuti anak bermain. Fasilitator mendampingi dan ikut mengobservasi para orang tua dalam mendampingi anak bermain.

\section{Pemaparan kembali}

Salah satu indikasi anak terbebas dari rasa trauma ketika anak mampu mengingat kembali peristiwa traumatik dengan lebih tenang (Handoyo, 2019). Tujuan kegiatan pada sesi ini adalah mengajarkan cara membiasakan anak mengingat peristiwa trauma dan menyiapkan kegiatan antisipasi bencana alam. Trauma muncul karena menganggap peristiwa yang dialami sebagai sesuatu yang luar biasa. Anak perlu diajak untuk lebih menerima peristiwa traumatik dengan kembali mengingat peristiwa traumatik agar dampak buruk trauma dapat dikurangi. Peristiwa traumatik juga dapat dijadikan pelajaran apabila mendeteksi muncul pertanda akan terjadi peristiwa traumatik, anak dapat mengantisipasi dengan tepat.

Pada sesi pemaparan para peserta masih diminta membagi diri dalam empat kelompok. Masing-masing kelompok diberikan satu set alat menggambar dan kertas untuk masingmasing peserta. Para peserta diminta untuk menggambar bebas namun di dalamnya menggambarkan situasi yang paling menyenangkan sekaligus kejadian traumatik yang pernah dialami.

\section{Keterampilan Mengubah Kebiasaan}

Perubahan yang paling mendasar adalah cara pandang terhadap bencana (Handoyo, 2019). Keterampilan mengubah kebiasaan dalam panduan pelaksanaan PMT ada pada bagian pemecahan masalah karena merupakan upaya penyelesaian yang dapat menjembatani antara ketakutan yang dipikirkan anak dan kehidupan dunia nyata. Tujuan dari materi pemecahan masalah adalah mengajak peserta untuk menjelaskan kepada anak cara melihat bencana dari sisi lain. Kegiatan diawali dengan pemateri menjelaskan sekilas tentang reframing. Orang tua perlu memperhatikan beberapa aspek seperti jarak bicara antara orang tua dan anak, komunikasi non-verbal seperti tatapan mata dan ekspresi wajah, serta pemilihan kata dan intonasi agar dapat melakukan reframing dengan baik. Peserta kemudian diminta untuk saling berpasangan. Masing-masing peserta yang berpasangan secara bergantian memerankan orang tua dan anak. Pemeran orang tua diminta mengajarkan kepada anak apabila anak tidak menanggung beban trauma sendiri. Orang tua juga harus menjelaskan sisi lain dari bencana alam yaitu bencana alam terjadi karena siklus alami yang harus mampu diantisipasi.

\section{Pembatasan}

Orang tua harus mampu memberikan kesempatan bagi anak untuk menghadapi rasa takut (Handoyo, 2019). Pelatihan dengan materi pembatasan diawali dengan memberi penjelasan tentang pentingnya memberi kesempatan bagi anak untuk menghadapi ketakutannya sendiri. Ketika memberi kesempatan bagi anak untuk menghadapi rasa takutnya, Fasilitator menekankan beberapa aspek yang perlu diperhatikan oleh peserta. Pertama adalah aspek nonverbal antara lain seperti tatapan mata, mimik ekspresi, serta gestur tubuh. Kedua adalah 
komunikasi verbal seperti pemilihan kata, rasionalisasi, volume dan intonasi, serta kecepatan bicara.

Peserta kemudian saling berpasangan untuk melakukan simulasi cara memberikan kesempatan bagi anak untuk menghadapi ketakutan sendiri. Ada beberapa kondisi yang dijadikan setting cara orang tua melakukan simulasi. Saat orang tua mencoba memberi kesempatan bagi anak untuk menghadapi rasa takut, tidak jarang akan mengalami kebimbangan dalam diri antara ingin memandirikan anak dan tidak tega membiarkan anak. Apabila berada posisi kebimbangan, orang tua harus mampu berfikir dengan jernih serta memiliki pertimbangan yang tepat. Membiarkan anak menghadapi ketakutan harus disesuaikan dengan usia anak. tindakan yang diterapkan pada anak usia di bawah lima tahun akan berbeda dengan tindakan yang diterapkan pada anak usia sekolah. Kunci utama dari upaya memandirikan anak adalah rasionalisasi yang dijelaskan kepada anak ketika orang tua harus secara terpaksa memberi kesempatan bagi anak untuk menghadapi rasa takutnya serta dengan memberi apresiasi saat anak berhasil menghadapi ketakutannya.

\section{Konsekuen}

Orang tua harus bisa konsisten dengan keputusan yang telah diambil atau diberikan kepada anak (Handoyo, 2019). Pelatihan pada sesi ini diawali dengan penjelasan dari fasilitator mengenai sikap konsekuen dan konsisten. Fasilitator juga membuka ruang diskusi bagi para peserta. Ketika dilakukan sesi diskusi muncul beberapa pertanyaan seperti Ibu SM yang menanyakan cara mengajak anak memahami kondisi orang tua yang tidak mampu mewujudkan janji. Seandainya orang tua sedang memiliki hambatan atau ada kebutuhan lain yang harus diprioritaskan peserta DS memberi usulan untuk menunda dan menjanjikan sesuatu yang lebih besar lagi dikemudian hari. Lain dengan Ibu ED yang mencontohkan agar anak diajak untuk menyaksikan sendiri kondisi orang tua bahkan Ibu ED memberi contoh untuk menunjukkan isi dompet yang terbatas sementara kebutuhan yang juga dimanfaatkan anak tetap harus ada, maka anak akan paham. Apabila anak sering dibohongi, maka secara tidak sadar orang tua mengajari anak untuk bohong. Membohongi anak juga tidak sejalan dengan rangkaian upaya menghadapi anak trauma karena dapat memunculkan rasa tidak percaya pada anak sementara kunci penanganan trauma anak adalah kepercayaan anak. Peserta YS menanyakan cara membuat janji yang baik dengan anak sekaligus antisipasi apabila janji tidak tercapai. Peserta TL memberikan pendapat apabila janji lebih baik bersifat jauh ke depan atau dalam jangka waktu yang relatif lama sehingga orang tua juga memiliki kesempatan untuk mempersiapkan realisasi janji. Disayangkan karena keterbatasan waktu sesi simulasi yang direncanakan secara berpasangan tidak dapat dilakukan. Meskipun demikian berdasarkan sesi diskusi fasilitator mengobservasi, para peserta mampu menunjukkan upaya konsekuen dan konsisten kepada anak.

\section{Hasil Penerapan}

Pada akhir kegiatan, dilakukan pembandingan data antara sebelum diberikan kegiatan pelatihan dan setelah kegiatan pelatihan. Penilaian dilakukan pada masing-masing aspek (materi layanan) dengan metode dan alat yang sama. Pengujian juga dilakukan menggunakan Uji Tanda.

Berdasarkan Tabel 2 diketahui, skor ${ }_{\text {hitung }}$ adalah 0,002. Karena 0,002<0,5 maka aspek validasi terbukti mengalami perubahan. Perubahan pada aspek validasi dapat ditafsirkan, para 
peserta mulai menunjukkan peningkatan pada kemampuan bersikap ketika menghadapi anak trauma memiliki probabilitas kecil karena pada awal telah berada pada posisi yang tinggi. Skor probabilitas pada aktivitas berpusat pada anak adalah 0,057. Apabila dituliskan maka $0,057<0,05$ sehingga aspek aktivitas berpusat pada anak terbukti mengalami perubahan. Disimpulkan, para peserta menunjukkan adanya perubahan pada kemampuan memberikan kebebasan anak untuk berekspresi dan memahami perasaan anak. Skor probabilitas pada aspek pemaparan adalah 0,001. Skor $0,001<0,05$ maka aspek pemaparan terbukti mengalami perubahan. Ditafsirkan, orang tua mampu menunjukkan perubahan positif dalam kemampuan mengajak anak mengingat kembali tentang peristiwa traumatik. Orang tua juga lebih mampu mengajarkan anak cara menghadapi situasi traumatik. Skor probabilitas pada aspek mengubah kebiasaan adalah 0,146. Apabila dituliskan maka 0,146<0,05 sehingga aspek mengubah kebiasaan terbukti mengalami perubahan. Para peserta lebih mampu mengajak anak melihat sisi lain dari peristiwa traumatik. Skor probabilitas pada aspek pembatasan adalah 0,012 sehingga $<0,05$. Ditafsirkan, aspek aktivitas berpusat pada anak terbukti mengalami perubahan. Peserta menjadi lebih berani memberikan kesempatan bagi anak untuk menghadapi ketakutan sendiri. Terakhir, skor probabilitas pada aspek konsekuen adalah 0,125. Skor $0,125<0,05$ sehingga aspek aktivitas berpusat pada anak terbukti mengalami perubahan. Peserta menjadi lebih konsekuen dengan kesepakatan yang telah dibuat bersama dengan anak. Peserta juga menjadi lebih konsisten dengan keputusan bersama, apabila orang tua harus menghukum anak, maka tetap dilakukan. Sebaliknya, apabila orang tua telah membuat janji, maka sedapat mungkin janji harus ditepati.

Tabel 2. Pengukuran hasil perubahan

\begin{tabular}{lcccc}
\hline \multicolumn{1}{c}{ Aspek } & Pretest & Posttest & Perubahan & Skor p \\
\hline Validasi & 7,94 & 10,00 & 2,06 & 0,002 \\
Aktivitas berpusat & 3,68 & 4,94 & 1,26 & 0,057 \\
Pemaparan & 3,69 & 4,69 & 1,00 & 0,001 \\
Mengubah kebiasaan & 3,31 & 4,13 & 0,82 & 0,146 \\
Pembatasan & 1,63 & 2,38 & 0,75 & 0,012 \\
Konsekuen & 3,44 & 4,19 & 0,85 & 0,125 \\
\hline
\end{tabular}

\section{KESIMPULAN}

Pelaksanaan pelatihan pengasuhan anak bagi ibu korban erupsi Merapi secara umum dapat berjalan sesuai dengan rencana. Secara pengujian statistik program pelatihan terbukti mampu meningkatkan keterampilan pengasuhan menghadapi anak trauma bagi ibu korban erupsi Merapi. Perubahan dalam sikap juga dipaparkan oleh para peserta. Pada masing-masing aspek juga terbukti memiliki peningkatan yang signifikan.

Secara umum para peserta menunjukkan antusiasme pada setiap pelaksanaan sesi. Antusiasme dapat dilihat dari fokus yang diberikan peserta saat mengikuti materi. Peserta juga mampu melaksanakan instruksi pada setiap sesi simulasi. Catatan khusus diberikan pada sesi pertama karena simulasi dilakukan oleh perwakilan peserta. Keadaan dapat dianggap wajar karena kemungkinan peserta merasa malu. Pada sesi selanjutnya peserta juga mampu melaksanakan simulasi dengan baik. 
Respon positif peserta mampu ditunjukkan hingga akhir program. Para peserta merasakan masih perlu mendapatkan materi serupa sebagai penguatan pada waktu-waktu selanjutnya. Selain itu peserta juga berharap pelatihan tidak sebatas dilakukan pada para warga yang memiliki anak usia SD dan SMP namun dapat diberikan kepada seluruh ibu di Pedukuhan Petung. Selain itu, besar harapan peserta, materi dapat disebar luaskan pada semua warga lain dan tidak terbatas kepada para Ibu namun juga para Bapak. Bagaimanapun juga dalam mengasuh anak perlu kerja sama antara peran Ibu dan Bapak. Penulis menyadari, melibatkan lebih banyak peserta menjadikan kegiatan yang dilakukan akan semakin bermanfaat. Melibatkan semua pihak yang terkait dalam pengasuhan akan menjadikan perubahan pada anak berjalan secara lebih efektif serta turut menjadikan kondisi keluarga lebih baik.

\section{Daftar Pustaka}

1. Afiati, E., Handoyo, A.W., Muhibah, S., \& Al Hakim, I. (2020). Terapi Bermain Bagi Siswa Korban Bencana Tsunami di Kecamatan Sumur Banten. Jurnal Penelitian Bimbingan dan Konseling, 5(1), 33-40. http://jurnal.untirta.ac.id/index.php/JPBK/article/view/7917

2. Butler, L.D., Carello, J., \& Maguin, E. (2017). Trauma, stress, and self-care in clinical training: Predictors of burnout, decline in health status, secondary traumatic stress symptoms, and compassion satisfaction. Psychological Trauma: Theory, Research, Practice, and Policy, 9(4), 416-424. https://doi.org/10.1037/tra0000187

3. Cobham, V.E., \& McDermott, B. (2014). Perceived Parenting Change and Child Posttraumatic Stress Following a Natural Disaster. Journal of Child and Adolescent Psychopharmacology, 24(1), 18-23. https://doi.org/10.1089/cap.2013.0051

4. Creech, S.K., \& Misca, G. (2017). Parenting with PTSD: A review of research on the influence of PTSD on parent-child functioning in military and veteran families. Frontiers in Psychology, 8, 1101. https://doi.org/10.3389/fpsyg.2017.01101

5. DeGangi, G.A., \& Kendall, A. (2008). Effective Parenting for the Hard-to-Manage Child. Routledge.

6. Eddy, J.M., Martinez, C.R., \& Burraston, B. (2013). A randomized controlled trial of a parent management training program for incarcerated parents: Proximal impacts. Monographs of the Society for Research in Child Development, 78(3), 75-93. https://doi.org/10.1111/mono.12022

7. Enebrink, P., Högström, J., Forster, M., \& Ghaderi, A. (2012). Internet-based parent management training: A randomized controlled study. Behaviour research and therapy, 50(4), 240-249. https://doi.org/10.1016/j.brat.2012.01.006

8. Feist, J., \& Feist, G. (2006). Theories of Personality. McGraw Hill.

9. Felton, J.W., Cole, D.W., \& Martin, N.C. (2013). Effects of Rumination on Child and Adolescent Depressive Reactions to a Natural Disaster: the 2010 Nashville Flood. Journal Abnormal Psychology, 122(1), 64-73. https://doi.org/10.1037/a0029303

10. Fossion, P., Leys, C., Kempenaers, C., Braun, S., Verbanck, P., \& Linkowski, P. (2013). Depression, anxiety and loss of resilience after multiple traumas: an illustration of a mediated moderation model of sensitization in a group of children who survived the Nazi Holocaust. Journal of affective disorders, 151(3), 973-979. https://doi.org/10.1016/j.jad.2013.08.018

11. Forgatch, M.S., \& Kjøbli, J. (2016). Parent management training—Oregon model: Adapting intervention with rigorous research. Family process, 55(3), 500-513. https://doi.org/10.1111/famp.12224

12. Hafstad, G.S., Haavind, H. \& Jensen, T.K. (2012). Parenting After a Natural Disaster: A Qualitative Study of Norwegian Families Surviving the 2004 Tsunami in Southeast Asia. Journal Child Family Study, 21, 293-302. https://doi.org/10.1007/s10826-011-9474-Z

13. Hall, C., \& Lindzey, G. (1985). Introduction to Theories of Personality. John Willey \& Sons. 
14. Handoyo, A.W. (2019). Studi Pola Pengasuhan Anak Para Ibu Korban Erupsi Merapi. Medikons: Jurnal Prodi Bimbingan dan Konseling Unisri Surakarta, 5(1). http://www.ejurnal.unisri.ac.id/index.php/mdk/article/view/2820

15. Hutchison, L., Feder, M., Abar, B., \& Winsler, A. (2016). Relations between parenting stress, parenting style, and child executive functioning for children with ADHD or autism. Journal of Child and Family Studies, 25(12), 3644-3656. https://doi.org/10.1007/s10826-016-0518-2

16. Kinchin, D. (2007). A guide to psychological debriefing: Managing emotional decompression and post-traumatic stress disorder. Jessica Kingsley Publishers.

17. Kottman, T. (2014). Play therapy: Basics and beyond. John Wiley \& Sons.

18. Mackler, J.S., Kelleher, R.T., Shanahan, L., Calkins, S.D., Keane, S.P., \& O'Brien, M. (2015). Parenting stress, parental reactions, and externalizing behavior from ages 4 to 10. Journal of Marriage and Family, 77(2), 388-406. https://doi.org/10.1111/jomf.12163

19. National Comision on Children and Disaster. (2010). Report to the President and Congress. Agency for Healthcare Research and Quality.

20. Newman, E., Pfefferbaum, B., Kirlic, N., Tett, R., Nelson, S., \& Liles, B. (2014). Meta-Analytic Review of Psychological Interventions for Children Survivors of Natural and Man-Made Disasters. Current Psychiatry Reports, 16(9), article 462. https://doi.org/10.1007/s11920-014$\underline{0462-\mathrm{Z}}$

21. Ollendick, T.H., Greene, R.W., Austin, K.E., Fraire, M.G., Halldorsdottir, T., Allen, K.B., \& Noguchi, R.J. (2016). Parent management training and collaborative \& proactive solutions: A randomized control trial for oppositional youth. Journal of Clinical Child \& Adolescent Psychology, 45(5), 591-604. https://doi.org/10.1080/15374416.2015.1004681

22. Roustit, C., Campoy, E., Chaix, B., \& Chauvin, P. (2010). Exploring mediating factors in the association between parental psychological distress and psychosocial maladjustment in adolescence. European child \& adolescent psychiatry, 19(7), 597-604. https://doi.org/10.1007/s00787-010-0094-8

23. Russell, S.T., Crockett, L.J., \& Chao, R.K. (2010). Introduction: Asian American parenting and parent-adolescent relationships. In Asian American parenting and parent-adolescent relationships (pp. 1-15). Springer.

24. Samuelson, K.W., Wilson, C.K., Padrón, E., Lee, S., \& Gavron, L. (2017). Maternal PTSD and children's adjustment: Parenting stress and emotional availability as proposed mediators. Journal of Clinical Psychology, 73(6), 693-706. https://doi.org/10.1002/jclp.22369

25. Santrock, J. (2011). Child Development. McGraw Hill.

26. Shreffler, K.M., Meadows, M.P., \& Davis, K.D. (2011). Firefighting and Fathering: WorkFamily Conflict, Parenting Stress, and Satisfaction with Parenting and Child Behavior. Fathering: A Journal of Theory, Research, and Practice About Men as Fathers, 9(2), 169-188. https://doi.org/10.3149/fth.0902.169

27. Sriskandarajah, V., Neuner, F., \& Catani, C. (2015). Parental Care Protects Traumatized Sri Lankan Children from Internalizing Behavior Problems. BMC Psychiatry, 15, article 203. https://doi.org/10.1186/s12888-015-0583-X

28. Sung, M., \& Park, J. (2012). The Effects of a Family Support Program Including Respite Care on Parenting Stress and Family Quality of Life Perceived by Primary Caregivers of Children with Disabilities in Korea. International Journal of Special Education, 27(3), 188-198. https://eric.ed.gov/?id=EJ1001071

29. Uji, M., Sakamoto, A., Adachi, K., \& Kitamura, T. (2014). The Impact of Authoritative, Authoritarian, and Permissive Parenting Styles on Children's Later Mental Health in Japan: Focusing on Parent and Child Gender. Journal of Child and Family Studies, 23, 293-302. https://doi.org/10.1007/s10826-013-9740-3

30. Wachlarowicz, M., Snyder, J., Low, S., Forgatch, M., \& DeGarmo, D. (2012). The Moderating effects of parent antisocial characteristics on the effects of Parent Management Training-Oregon (PMTO $\left.{ }^{\mathrm{TM}}\right)$. Prevention Science, 13, 229-240. https://doi.org/10.1007/s11121-011-0262-1 